Superconducting Helical Snake Magnet for the AGS

E. Willen, M. Anerella, J. Escallier, G. Ganetis, A. Ghosh, R. Gupta, M. Harrison, A. Jain, A. Luccio, W. Mackay, A. Marone, J. Muratore, S. Plate, T. Roser, N. Tsoupas, P. Wanderer

May 16, 2005

Superconducting Magnet Division

Brookhaven National Laboratory

Operated by

Brookhaven Science Associates

Upton, NY 11973

Under Contract with the United States Department of Energy

Contract Number DE-AC02-98CH10886 


\section{DISCLAIMER}

This report was prepared as an account of work sponsored by an agency of the United States Government. Neither the United States Government nor any agency thereof, nor any of their employees, nor any of their contractors, subcontractors or their employees, makes any warranty, express or implied, or assumes any legal liability or responsibility for the accuracy, completeness, or any third party's use or the results of such use of any information, apparatus, product, or process disclosed, or represents that its use would not infringe privately owned rights. Reference herein to any specific commercial product, process, or service by trade name, trademark, manufacturer, or otherwise, does not necessary constitute or imply its endorsement, recommendation, or favoring by the United States Government or any agency thereof or its contractors or subcontractors. The views and opinions of authors expresses herein do not necessarily state to reflect those of the United States Government or any agency thereof. 
PAC05, Knoxville, May 16-20, 2005

\title{
SUPERCONDUCTING HELICAL SNAKE MAGNET FOR THE AGS*
}

\author{
Erich Willen", Michael Anerella, John Escallier, George Ganetis, Arup Ghosh, Ramesh Gupta, \\ Michael Harrison, Animesh Jain, Alfredo Luccio, William MacKay, Andrew Marone, Joseph \\ Muratore, Stephen Plate, Thomas Roser, Nicholaos Tsoupas, and Peter Wanderer \\ Brookhaven National Laboratory, Upton, NY 11973-5000 \\ Masahiro Okamura, RIKEN, Saitama, Japan
}

\begin{abstract}
A superconducting helical magnet has been built for polarized proton acceleration in the Brookhaven AGS. This "partial Snake" magnet will help to reduce the loss of polarization of the beam due to machine resonances. It is a $3 \mathrm{~T}$ magnet some $1940 \mathrm{~mm}$ in magnetic length in which the dipole field rotates with a pitch of 0.2053 degrees $/ \mathrm{mm}$ for $1154 \mathrm{~mm}$ in the center and a pitch of 0.3920 degrees $/ \mathrm{mm}$ for $393 \mathrm{~mm}$ in each end. The coil cross-section is made of two slotted cylinders containing superconductor. In order to minimize residual offsets and deflections of the beam on its orbit through the Snake, a careful balancing of the coil parameters was necessary. In addition to the main helical coils, a solenoid winding was built on the cold bore tube inside the main coils to compensate for the axial component of the field that is experienced by the beam when it is off-axis in this helical magnet. Also, two dipole corrector magnets were placed on the same tube with the solenoid. A low heat leak cryostat was built so that the magnet can operate in the AGS cooled by several cryocoolers. The design, construction and performance of this unique magnet will be summarized.
\end{abstract}

\section{INTRODUCTION}

The superconducting AGS snake magnet is a strong partial Siberian snake able to eliminate depolarization from all spin resonances [1]. The limited space available in the AGS lattice dictated a compact design consisting of a sequence of three dipole helices with differing pitches arranged to give zero net orbit offset and angle. The integral of the dipole field absolute value at $3.072 \mathrm{~T}, 349$ A (full field) is $6.169 \mathrm{~T} \cdot \mathrm{m}$. At $2.5 \mathrm{Gev}$ injection energy, this would give a spin rotation angle of about $60^{\circ}(33 \%$ snake). Achieving the desired parameters for the strength and length of each helix required the iterative generation of a field map with Opera-3D, then the tracking of a particle on its orbit through the magnet, then adjustment of the magnet design [2]. A second study resulted in a somewhat different design than reported here [3]. Included in the magnet, in addition to the helical fields, is a solenoid (at full helical field, $0.613 \mathrm{~T} \cdot \mathrm{m}$ axial field on the beam orbit, $0.82 \mathrm{~m}$ long, 2 layer, 1360 total turns) that nearly cancels the solenoid component of the helical field in order to reduce $x, y$ betatron coupling of the beam. Also

\footnotetext{
* This manuscript has been authored by Brookhaven Science Associates, LLC under US DOE contract DE-AC02-98CH1-886. The US government retains, and the publisher, by accepting the article for publication, acknowledges, a world-wide license to publish or reproduce the published form of this manuscript, or allow others to do so, for US government purposes.

\#willen@bnl.gov
}

included are dipole correctors [4] at each end $(0.008 \mathrm{~T} \cdot \mathrm{m}$ (a. $25 \mathrm{~A}, 0.3 \mathrm{~m}$ long, 195 turns/quadrant) to allow vertical steering of the beam.

\section{CONSTRUCTION}

Construction was similar to that used for the earlier RHIC snakes and spin rotators $[5,6]$. The superconductor used was Kapton-wrapped 6-around-1 cable, one $\mathrm{mm}$ in diameter, made of NbTi wires with $2.5 / 1 \mathrm{Cu} / \mathrm{SC}$ ratio. The two concentric coils (one is shown in Fig. 1) were made

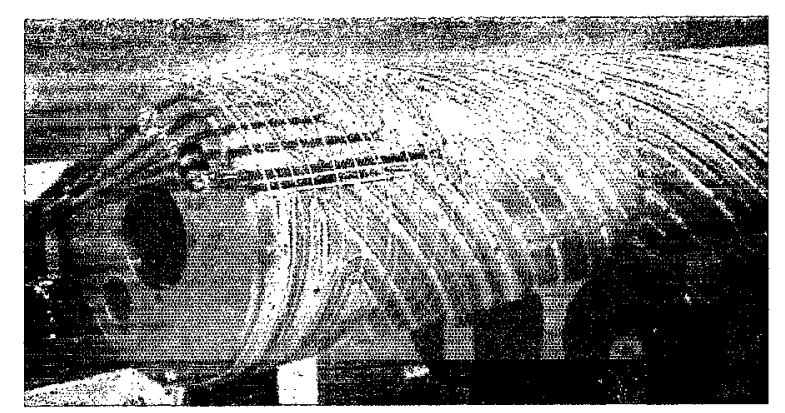

Figure 1 Photo of the inner coil. The various windings were complete but filler epoxy had not yet been applied.

by placing the cable into slots milled into thick-walled aluminum cylinders. There are a total of 20 slots, 18 filled with 108 turns and two (the inner coil pole slots) with 60 turns, for a total of 2064 turns in the coils. These were mounted into a yoke made of single-piece iron laminations. For this magnet, a number of improvements were made in the fabrication process to improve electrical reliability and to ensure the required accuracy in the machining of the slots [7].

The helical dipole and solenoid windings are connected in series because they are designed to operate at the same time with the same current. However, a third lead is provided to allow separate control. Four $50 \mathrm{~A}$ leads are included to control the dipole correctors, which operate with up to $40 \mathrm{~A}$. Quench protection is provided by redundant circuits that power strip heaters atop the dipole and solenoid windings in their non-end regions. Several spot heaters and voltage taps were included to allow a study of magnet temperatures during quench testing. Warm-up heaters in the yoke operating at several $\mathrm{kW}$, connected with retractable leads to reduce heat leak to the cold mass, reduce the time required for magnet warm-up. Many Cernox temperature sensors, several level probes, and a helium bath heater give knowledge and control of the cryogenic environment in the magnet. A photo of the nearly complete cold mass is shown in Fig. 2. 


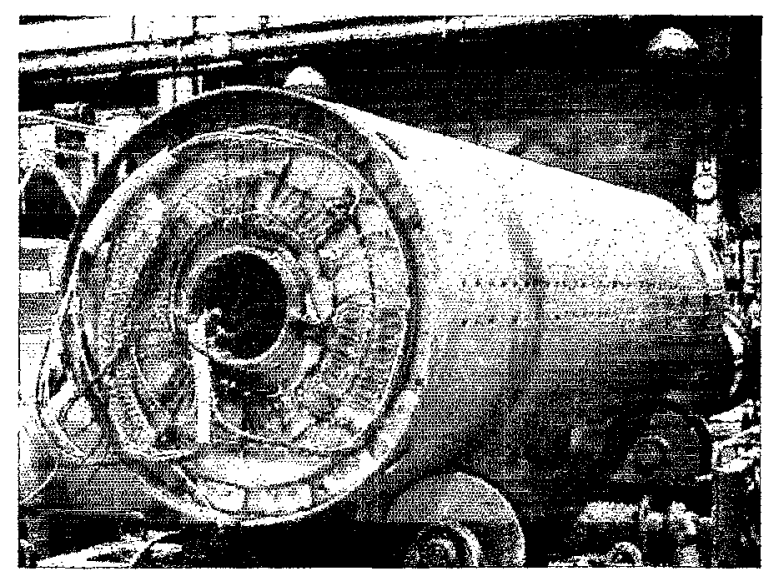

Figure 2 The nearly completed cold mass before closure of the helium containment shell in the ends. The small holes along the length are for helium circulation.

The cold mass is suspended in its cryostat with eight fiberglass straps. Intermediate temperature aluminum shields including those surrounding the cold mass and inside the bore of the magnet, heat intercepts on the suspension straps and leads, and careful placement of superinsulation minimize the heat leak to the $4.5 \mathrm{~K}$ parts. The shield inside the bore is segmented to reduce large eddy current forces during quench. The current is carried to the various coils on optimized copper buses and then on commercially available High Temperature Superconductor (HTS) leads. The quench protection heater wires and all the instrumentation wires are minimum-gauge copper, phosphor-bronze or stainless.

The magnet is designed to operate with up to four cryocoolers (Sumitomo RDK-415D) that each provide 1.5 $\mathrm{W}$ cooling at $4.2 \mathrm{~K}\left(2^{\text {nd }}\right.$ stage $)$ and $45 \mathrm{~W}$ at $50 \mathrm{~K}$. The second stage surface of each cryocooler is attached through copper straps to a large copper block atop the cold mass, where the helium inside the coldmass is recondensed as it absorbs heat and vaporizes. The initial cooldown is accomplished with cold nitrogen circulated through a separate cooling loop mounted on the cold mass shell and the shields. Cold helium from a dewar is then circulated through the cold mass in carefully designed passages to optimize the heat transfer. When cold, the cryocoolers maintain the required temperatures, but piping has been included to also allow operation from dewars using a trickle-fill system for both the helium to the cold mass and the liquid nitrogen to the shields.

In operation, the calculated heat load of the magnet is $2.2 \mathrm{~W}$ to $4.5 \mathrm{~K}$ and $85 \mathrm{~W}$ to $60 \mathrm{~K}$. Initial experience indicates ballpark performance. With a cold mass of 5876 $\mathrm{kg}$, at least $1238 \mathrm{I}$ of liquid nitrogen and 6621 of liquid helium are required to cool the magnet, depending on the flow rates used. When the magnet quenches at $350 \mathrm{~A}, 400$ $\mathrm{kJ}$ of heat are released into the magnet and the helium is ejected into the vent. At least 491 of liquid helium are required to remove this heat, and an additional 1091 to refill the magnet. This must be supplied from external dewars as the cryocoolers would take too long to remove this much heat.

\section{PERFORMANCE}

The magnet was tested several times: initially in a vertical dewar, again in a vertical dewar after a short was repaired, then as a completed magnet in its horizontal dewar.

\section{Quench History}

After seven training quenches in the range $289 \mathrm{~A}$ to 332 $\mathrm{A}$, the dipole helix reached $373 \mathrm{~A}$, exceeding the goal of $350 \mathrm{~A}$. With the dipole helix at $350 \mathrm{~A}$, the solenoid winding required eight quenches before exceeding $350 \mathrm{~A}$. This winding sometimes quenches a little below $350 \mathrm{~A}$ so a current limit of $320 \mathrm{~A}$ has been adopted, still acceptable for operations. The large axial Lorentz pressure on each turn of the winding, 1 MPa (145 psi), probably accounts for this limit. It did not quench up to $385 \mathrm{~A}$ without the dipole field. With $350 \mathrm{~A}$ in the dipole coil, the corrector coils did not quench up to $\pm 45 \mathrm{~A}$. The spot heater quenches indicated a maximum coil temperature of $240 \mathrm{~K}$ in the least favorable combination of coil current (375 A) and quench position (midplane end turn), with most quenches well below $200 \mathrm{~K}$.

\section{Magnetic Field}

The field measurements show that the magnet performs as expected from the Opera-3D calculations. This means that the computer model can reliably be used for tracking and other calculations. The integral field is below 0.01 $\mathrm{T} \cdot \mathrm{m}$, the most important requirement for this magnet. The transfer functions of the main helical dipole and the skew dipole correctors are as expected. The solenoid winding field was not separately measured; its calculated value is used. Figs. 3 through 7 show various of the measurements performed.

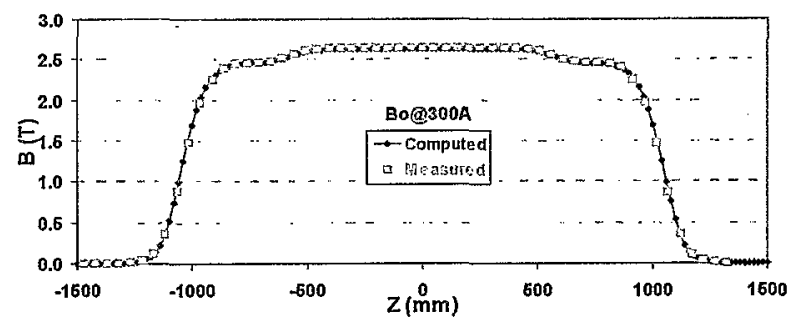

Figure 3 Field in the magnet along its length. The field is lower in the region of greater pitch.

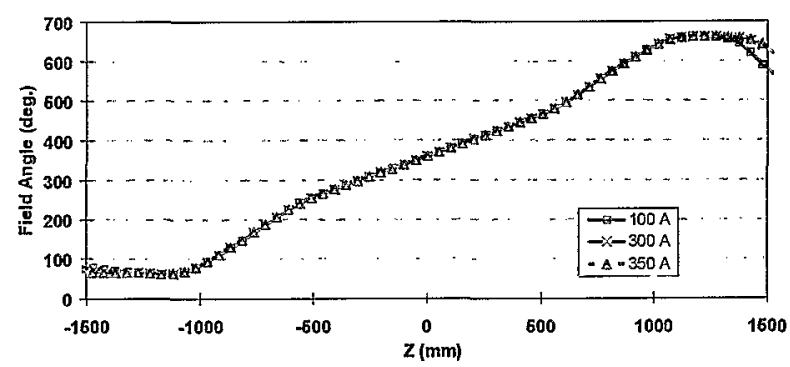

Figure 4 The angle of the field along the length of the magnet. The center region pitch is half that in the ends. 


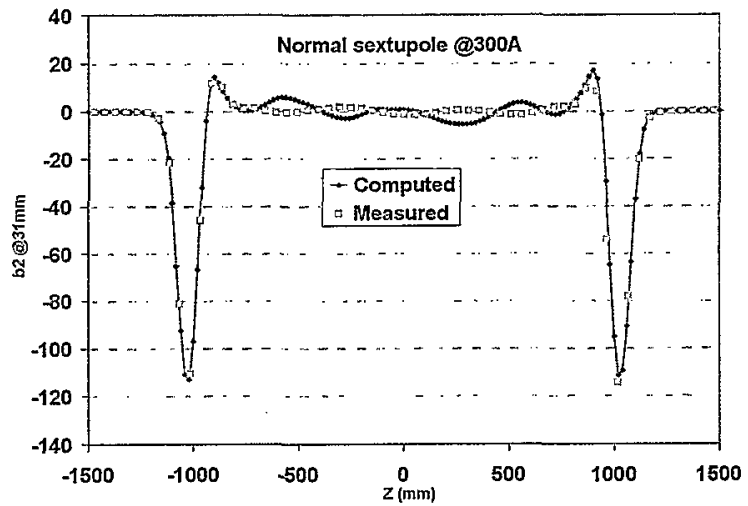

Figure 5 The sextupole component measured stepwise with a tangential measuring coil $51 \mathrm{~mm}$ long, $r=34 \mathrm{~mm}$.

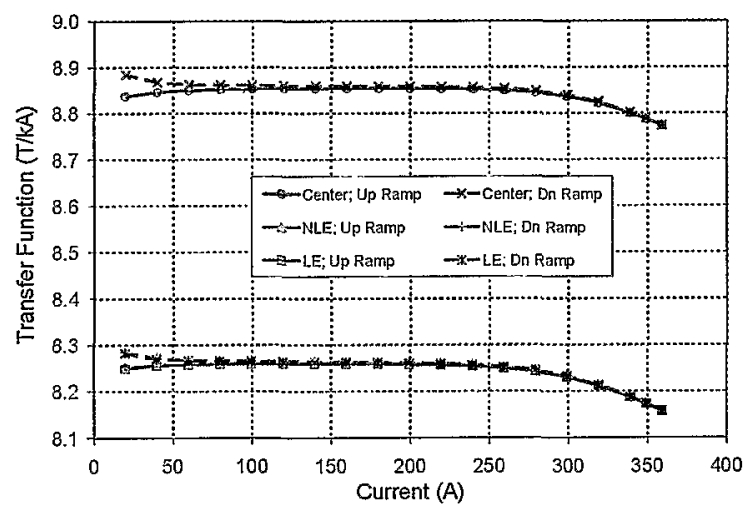

Figure 6 Excitation curves centered in the different pitch regions, measured with the rotating tangential coil.

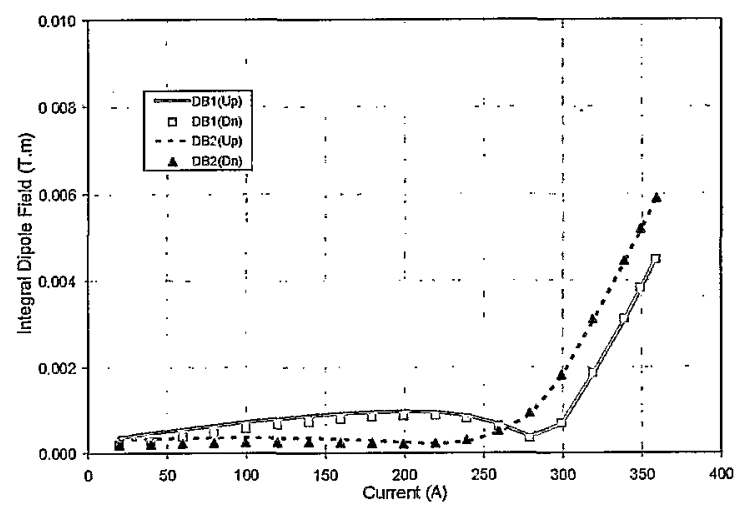

Figure 7 Integral dipole field measured with two different windings of a full-length rotating coil. The maximum integral value is well below the limit of $0.01 \mathrm{~T} \cdot \mathrm{m}$.

\section{SUMMARY}

The tests showed that the magnet met all requirements for electrical, magnetic, alignment and cryogenic performance. It has been installed in the AGS and is being incorporated into the operations for polarized protons. A picture of the installed magnet is shown in Fig. 8.

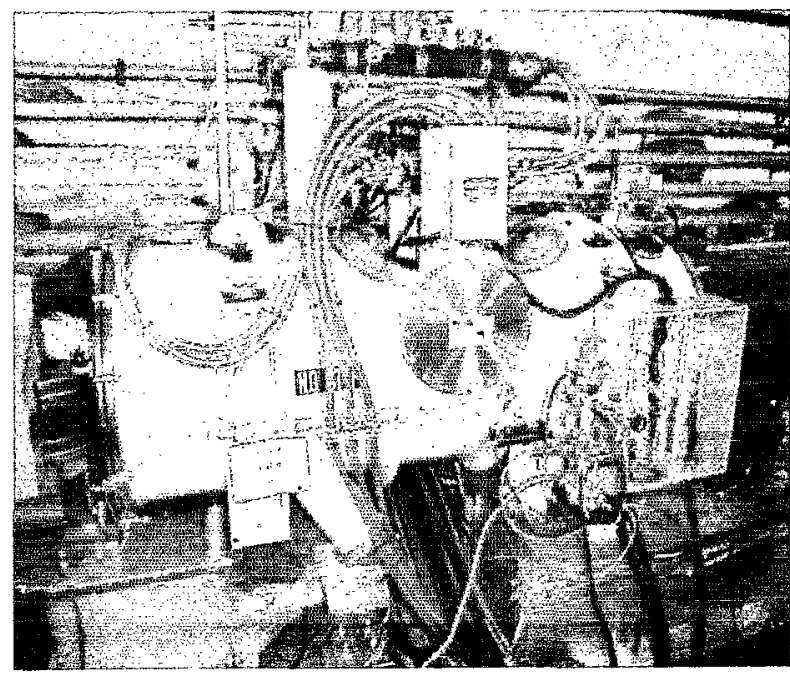

Figure $8 \mathrm{~A}$ photo of the completed snake magnet installed in the AGS ring (Section A20). The cryocooler head connections are behind and to the left of the white box in the top center.

\section{REFERENCES}

[1] T. Roser, L. Ahrens, M. Bai, E.D. Courant, J. Glen, R.C. Gupta; H. Huang, A.U. Luccio, W. MacKay, N. Tsoupas, E. Willen, M. Okamura, Acceleration of Polarized Beams Using Multiple Strong Partial Siberian Snakes, EPAC04, Lucerne, July, 2004.

[2] R. Gupta, A. Luccio, W. MacKay, G. Morgan, K. Power, T. Roser, E. Willen, M. Okamura, Magnetic Design of a Superconducting AGS Snake, PAC03, Portland, May, 2003; A. Luccio, R. Gupta, W. MacKay, T. Roser, Cold AGS Snake Optimization by Modeling, C-A/AP \#128, Brookhaven, December, 2003.

[3] M. Okamura, T. Katayama, T. Tominaka, T. Ohkawa, R. Gupta, A. Luccio, W. MacKay, T. Roser, E. Willen, Design Study of a Partial Snake for the AGS, EPAC02, Paris, June, 2002.

[4] R. Gupta, Optimum Integral Design for Maximizing Field in Short Magnets, ASC04, Jackonsville, October, 2004.

[5] E. Willen, R. Gupta, A. Jain, E. Kelly, G Morgan, J. Muratore, R. Thomas, A Helical Magnet Design for RHIC, PAC97, Vancouver, May, 1997.

[6] E. Willen, E. Kelly, M. Anerella, J. Escallier, G. Ganetis, A. Ghosh, A. Jain, A. Marone, G. Morgan, J. Muratore, A. Prodell, P. Wanderer, Construction of Helical Magnets for RHIC, PAC99, New York, March/April, 1999.

[7] M. Anerella, R. Gupta, P. Kovach, A. Marone, S. Plate, K. Power, J. Schmalzle, E. Willen, Engineering of the AGS Snake Coil Assembly, PAC03, Portland, May, 2003. 